\title{
Hicks neutral technical change revisited: CES production function and information of general order
}

Citation for published version (APA):

Dupuy, A. (2006). Hicks neutral technical change revisited: CES production function and information of general order. B E Journal of Macroeconomics, 6(2), 1-24. https://doi.org/10.2202/1534-5998.1339

Document status and date:

Published: 01/01/2006

DOI:

10.2202/1534-5998.1339

Document Version:

Publisher's PDF, also known as Version of record

\section{Please check the document version of this publication:}

- A submitted manuscript is the version of the article upon submission and before peer-review. There can be important differences between the submitted version and the official published version of record.

People interested in the research are advised to contact the author for the final version of the publication, or visit the DOI to the publisher's website.

- The final author version and the galley proof are versions of the publication after peer review.

- The final published version features the final layout of the paper including the volume, issue and page numbers.

Link to publication

\footnotetext{
General rights rights.

- You may freely distribute the URL identifying the publication in the public portal. please follow below link for the End User Agreement:

www.umlib.nl/taverne-license

Take down policy

If you believe that this document breaches copyright please contact us at:

repository@maastrichtuniversity.nl

providing details and we will investigate your claim.
}

Copyright and moral rights for the publications made accessible in the public portal are retained by the authors and/or other copyright owners and it is a condition of accessing publications that users recognise and abide by the legal requirements associated with these

- Users may download and print one copy of any publication from the public portal for the purpose of private study or research.

- You may not further distribute the material or use it for any profit-making activity or commercial gain

If the publication is distributed under the terms of Article $25 \mathrm{fa}$ of the Dutch Copyright Act, indicated by the "Taverne" license above, 


\title{
Topics in Macroeconomics
}

Volume 6, Issue 2

2006

Article 2

\section{Hicks Neutral Technical Change Revisited: CES Production Function and Information of General Order}

\author{
Arnaud Dupuy*
}

*Maastricht University, a.dupuy@ roa.unimaas.nl

Copyright (c)2006 The Berkeley Electronic Press. All rights reserved. 


\title{
Hicks Neutral Technical Change Revisited: CES Production Function and Information of General Order*
}

\author{
Arnaud Dupuy
}

\begin{abstract}
In this paper, I show that Hicks neutral technical change is identified as the information of order sigma obtained if the distribution of factor prices is replaced by the distribution of factor efficiency parameters. Together with Solow's residual, the information method enables us to distinguish between the neutral and non neutral part of technical and organizational changes. An empirical evaluation of both methods is provided using Jorgenson's (2001) US data for the period 1948-1999. The main results of the paper are that i) both neutral and non neutral technical change have occurred in the US in the period 1948-1999 and ii) 3/4th of the productivity slowdown observed in the 70s and $80 \mathrm{~s}$ is due to a deceleration in the contribution of non neutral technical changes.
\end{abstract}

KEYWORDS: neutral and non neutral technical change, Solow's residual, information of general order

${ }^{*}$ The author thanks Michael Sattinger, the Editor John Leahy and two anonymous referees for helpful comments on earlier drafts of this paper. Corresponding address. Maastricht University, P.O. Box 616, MD 6200 MD, Maastricht, the Netherlands. E-mail: a.dupuy@ roa.unimaas.nl. Tel: +31433883735. 
Dupuy: Hicks Neutral Technical Change Revisited

\section{Introduction}

Measuring productivity growth has been one of the main concerns of a great many economists in the last 100 years. The tool used most often in the literature, still today, to measure total productivity ${ }^{1}$ dates back to Solow's (1957) seminal paper $^{2}$ in which he merged the traditional national income measurement with the production function concept. The growth accounting method proposed by Solow (1957) measures residual output growth as the growth of output not accounted for by the growth of factors that produce output. Suppose output $Y$ is produced with technology $F\left(X_{1}, \ldots, X_{n} ; t\right)$, i.e. a production function with $n$ inputs and time varying technology, then Solow's residual $S R$ is derived by totally differentiating $F$ with respect to time and dividing by total output $Y$, to obtain $S R \equiv \frac{\partial F / \partial t}{F}=$ $\frac{\dot{Y}}{Y}-\sum_{i} E_{Y X_{i}} \frac{\dot{X}_{i}}{X_{i}}$ where $E_{Y X_{i}} \equiv \frac{\partial F}{\partial X_{i}} \frac{X_{i}}{F}$ are the elasticities of output with respect to the various input factors. ${ }^{3}$

Articulated in this production function framework, the Solow residual $(S R$ from now on) is often identified as Hicks neutral technical change (see Hall (1988) p. 931 for instance) or disembodied technical change by assuming that technical changes leave the marginal rate of substitution between input factors unaffected, i.e. assuming that $F\left(X_{1}, \ldots, X_{n} ; t\right)=A(t) f\left(X_{1}, \ldots, X_{n}\right)$ with $\partial f / \partial t=0$. However, recent empirical evidence (see for instance Castro and Coen-Pirani (2005) and Dupuy and Marey (2004)) shows that the production function shifted in a non neutral way over the last decades due to technical and organizational changes. ${ }^{4}$ This suggests that $S R$ calculated for the US does not only capture Hicks neutral technical changes but also the effects of technical changes on the marginal rate of substitution. Rewriting $F\left(X_{1}, \ldots, X_{n} ; t\right)=A(t) f\left(X_{1}, \ldots, X_{n} ; t\right)$ so that changes in $f$ over time are non neutral in Hicksian sense, $S R$ can be decomposed into a neutral and a non neutral part, $S R \equiv \frac{\partial F / \partial t}{F}=\frac{\dot{A}}{A}+\frac{\partial f / \partial t}{f}$.

The aim of this paper is to evaluate the extent to which technical changes as measured by $S R$ capture technical changes that are Hicks neutral, i.e. $\frac{\dot{A}}{A}$. The theoretical contribution of this paper is to provide an alternative interpretation of Hicks neutral technical change building on the dual approach to growth ac-

\footnotetext{
${ }^{1}$ See Griliches (1996) for a historical note on "the discovery of the residual".

${ }^{2}$ In his article, Griliches notes that estimates of aggregate technical change date back to Copeland in 1937 and Tinbergen in 1942.

${ }^{3}$ Under constant returns to scale, $\sum_{i} E_{Y X_{i}}=1$ holds.

${ }^{4}$ These shifts in the production function certainly did not leave the marginal rate of substitution between input factors unaffected. Castro and Coen-Pirani (2005) show significant empirical evidence for a decrease in the capital-skill complementarity in the US in the period 1979-2003 whereas Dupuy and Marey (2004) indicate that the elasticity of substitution between skilled and unskilled labor has decreased at the end of the 70s and increased at the beginning of the 90s in the US. As demonstrated by de La Grandville (1989) and later proved by Klump and de La Granville (2000), Papageorgiou and Saam (2005) and Dupuy and de Grip (2006), these changes in the marginal rate of substitution in general and in the elasticity of susbtitution in particular affect output growth.
} 
counting exposed by Jorgenson and Griliches (1967) and Shapiro (1987). As in Solow (1957) and Jorgenson and Griliches (1967), I derive Hicks neutral technical change assuming perfect competition in the factor and output markets. Using a general nested CES production function with elasticity parameter $\sigma$, I then show that Hicks neutral technical change is identified as the information ${ }^{5}$ of order $\sigma$ obtained if the distribution of factor prices is replaced by the distribution of factor efficiency parameters. Since the information method depends merely on factor prices it belongs to the general dual approach of productivity. ${ }^{6}$

The distinction between the neutral $\frac{\dot{A}}{A}$ and non neutral $\frac{\partial f / \partial t}{f}$ part of $S R$ is only possible if one knows the shape of the function $f$ over time and therefore requires the non trivial estimation of the function $f$ over time. Under perfect competition, the structural parameters of the function $f$ can be estimated by estimation of the system of relative demand functions $\frac{\partial f / \partial X_{i}}{\partial f / \partial X_{j}}=\frac{p_{i}}{p_{j}}$ where $p_{i}$ is the real price of factor $X_{i}$. Once the parameters of the function $f$ are estimated, the level of Hicks neutral technical change $A(t)$ can be retrieved directly from the data on factor prices. Using Jorgenson's (2001) US data for the period 1948-1999, I estimate the structural parameters of the model allowing for technical change to be neutral and non neutral in Hicksian sense. The main results of the paper are that i) both neutral and non neutral technical changes have occurred in the US in the period 1948-1999 as the null hypothesis of equality of both $S R$ and the information measure is strongly rejected, even in subperiods and ii) while $S R$ drops by 0.76 percentage points after 1973 as already documented in Jorgenson (2001), the information measure of neutral technical change remains fairly stable so that $3 / 4^{\text {th }}$ of the productivity slowdown observed in the 70 s and 80 s is due to a deceleration in the contribution of non neutral technical changes.

As pointed out early in the related literature, measured using national income data, $S R$ is "a measure of our ignorance" (Abramovitz (1956) p.11) and has been shown to be very sensitive to measurement errors in factors and output ${ }^{7}$ and departures from the assumptions upon which its derivation relies, namely perfect competition in the factors and output markets and constant returns to scale. ${ }^{8}$ Especially output measurement errors have been discussed in the recent literature. Griliches (1996) argued that output measurement errors have been at the source of the productivity slowdown observed from the early 70 s to the mid90s, decades characterized by major investments in computer and information-

\footnotetext{
${ }^{5}$ Theil (1965 and 1967) was the first to bring information theory (see Shannon and Weaver (1949) for instance) and economic theory together. Footprints of information theory in economic theory are mainly seen in the measures of income inequality (Gini coefficient for instance is the exponential of the information of order 2), the measures of market power and industryconcentration and more recently indicators of product variety (see Straathof (2005)).

${ }^{6}$ See also Hsieh (1999), Jorgenson and Stiroh (2000), Oliner and Sichel (2000) and Aiyar and Dalgaard (2004) for previous studies using the dual approach to growth accounting.

${ }^{7}$ See Baily and Gordon (1988) for instance.

${ }^{8}$ See Hall (1988) for instance.
} 
processing equipment leading to the so called "productivity paradox." Although, recent quantitative evidence derived by Sichel (1997) shows that output measurement errors may have accounted for at most 0.23 percentage points in (or $20 \%$ of) the productivity slowdown. This paper contributes to this discussion by identifying the $S R$ slowdown as being merely due to a deceleration in non neutral technical change $\frac{\partial f / \partial t}{f}$ after 1973. This empirical result is in sharp contrast with the standard assumption in output growth models that technical changes are merely captured by changes in the stock of ideas or knowledge $A(t)$-although the source of changes in the stock $A(t)$ varies across models, R\&D activities in Romer (1990) or population growth in Jones (1999) - neglecting the possibility that technical and organizational changes might also affect the marginal rate of substitution between input factors. The evidence shown in this paper indicates that the major investments in computer and information-processing equipment made after 1973 did contribute to maintain the growth of the stock of ideas at its previous rate (no productivity paradox) but changed the marginal rate of substitution between factors of production so that productivity slowed down.

This paper also relates to the concept of elasticity of substitution. In the literature, the concept of elasticity of substitution introduced by John Hicks (1932) has been followed by a long standing search for the true generalized elasticity of substitution in the more than 2-input context. (see Allen (1938), Hicks (1970), Sato (1973) and Blackorby and Russel (1989)) This quest seems to have ended in 1989 with Blackorby and Russel's (1989) paper in which they show that the Morishima elasticity of substitution "preserves the salient characteristics of the original Hicksian concept" in the n-input case. In this paper I provide a new interpretation of the elasticity of substitution that has been missing in the literature. I take an information perspective and show that the $\sigma$ parameter, known in the Neoclassical CES technology as the elasticity of substitution is known in the information literature, see Shannon and Weaver (1949) for instance, as the order of information. The original Hicksian definition of $\sigma$ is the percentage change in the relative demand for two factors in response to a 1 percent change in the relative marginal productivity of these two inputs. In other words, $\sigma$ measures the distance between variation in the vector of factor quantity and variation in the vector of factor prices. In the information theory, the larger $\sigma$, the less uncertainty about future factor prices and therefore the more information is to be expected from observing differences between factor efficiencies and future factor prices.

The remainder of the paper is organized as follows. In section 2, I introduce the concept of entropy and information of general order $\alpha$. In section 3, I show that Hicks neutral technical change derived from the standard Neoclassical CES production technology with perfect competition is identified as the function of information of general order $\sigma$ where $\sigma$ is also the elasticity of substitution between factors and provide an intuitive interpretation. In section 4, I use data for the US economy in the span 1948-1999 and evaluate the respective contribution of 
neutral and non neutral technical change to output growth. Section 5 concludes.

\section{Entropy and information of general order $\alpha$}

Direct message

Suppose one runs an experiment for which there are $n$ possible events, say $E_{1}, \ldots, E_{n}$. Let $P=\left(p_{1}, p_{2}, \ldots, p_{n}\right)$ be the probability distribution associated to this experiment, with $p_{i} \geq 0 \forall i$ and $\sum_{i} p_{i}=1$. Shannon and Weaver (1949) define the entropy of the distribution $P, H[P]$, as the amount of uncertainty concerning the outcome of an experiment for which the possible outcome has probability $P$ reads as:

$$
H[P]=\sum_{i} p_{i} \ln \frac{1}{p_{i}}
$$

Generalizing this result, Renyi (1961) introduces the entropy of general order $\alpha, \alpha>0$.

$$
H_{\alpha}[P]=\frac{1}{1-\alpha} \ln \sum_{i} p_{i}^{\alpha}
$$

with $\lim _{\alpha \rightarrow 1} H_{\alpha}[P]=H[P]$.

The entropy of general order $\alpha$ is i) maximum and equal to $\ln n$ when each event $i$ has equal probability to occur, i.e. $p_{i}=1 / n \forall i$ and minimum and equal to 0 when one event $i$ has probability 1 to occur. The concept of entropy is also used to measure "the amount of information we get when we observe the result of an experiment (depending on chance)", Renyi (1961), p.553. Indeed, the entropy is minimized when we know with certainty the result of the experiment (one event is certain to occur the other certain not to occur), which means that there is little information to expect from hearing the result of the experiment. To put it in Theil's words:

The less uncertainty there is now [about future events], the less information is to be expected when we hear what actually happened. Theil (1967), p. 25.

\section{Indirect message}

Suppose that instead of receiving a direct message containing the outcome of the experiment, one receives an indirect message indicating that the probability 
Dupuy: Hicks Neutral Technical Change Revisited

distribution has changed. Some events have become more probable and some less. The amount of information $I_{\alpha}(Q \mid P)$ contained in this message that is, the information we obtain when the prior probability distribution $P$ is replaced by the posterior probability distribution $Q$, with $Q=\left(q_{1}, q_{2}, \ldots, q_{n}\right), q_{i} \geq 0 \forall i$ and $\sum_{i} q_{i}=1$, is equal to the relative entropy $E_{\alpha}[Q \mid P]$.

In Shannon's case, the relative entropy (of order one) is defined as:

$$
I[Q \mid P] \equiv E[Q \mid P]=\sum_{i} q_{i} \ln \frac{q_{i}}{p_{i}}
$$

Renyi's (1961) generalized information measure of general order $\alpha$ reads as follows:

$$
I_{\alpha}[Q \mid P] \equiv E_{\alpha}[Q \mid P]=\frac{1}{\alpha-1} \ln \sum_{i} \frac{q_{i}^{\alpha}}{p_{i}^{\alpha-1}}
$$

with Shannon's measure as special case, $\lim _{\alpha \rightarrow 1} I_{\alpha}[Q \mid P]=I[Q \mid P]$.

When both distributions are equal, the amount of information of the indirect message is equal to 0 . In contrast, the information tends to infinity when in both distributions a different event is certain to occur, i.e. $q_{i}=1$ and $q_{j}=0$ for all $j \neq i$ and $p_{k}=1, k \neq i$ and $p_{j}=0$ for all $j \neq k$. Intuitively, the information of order $\alpha, I_{\alpha}[Q \mid P]$, measures the inequality between the distributions $Q$ and $P$.

I am left with an interpretation of the order of information. I propose to illustrate the role played by the order of information graphically. To this aim I consider two distributions $Q$ and $P$ indicating the probability that an object is in either state 1 or 2 , so that $Q=(q, 1-q)$ and $P=(p, 1-p)$. I choose to plot the information of order $\alpha$ in the $\left\langle q ; I_{\alpha}>\right.$ space, conditional on $P$. For the sake of simplicity I choose $p=0.5$ and plot in Figure 1 the information of order $\alpha=0.1$, $0.5,1,2$ and 10, as the probability $q$ increases from 0 to 1 .

$<$ Insert Figure 1>

The figure indicates that the larger the order $\alpha$, the faster the information increases as the distribution $Q$ diverges from the distribution $P$. In other words, the larger $\alpha$, the more information is to be expected from the posterior distribution $Q$, ceteris paribus.

\section{CES production functions}

Single level CES production functions 
Consider an economy where, at time $t$, identical firms produce output level $Y_{t}$ using a CES technology ${ }^{9}$ with constant returns to scale, and $m$ factors of production, denoted $X_{i t}$. Assume further that all factors are supplied inelastically.

$$
Y_{t}=F_{t}\left(X_{1 t}, \ldots, X_{m t}\right)=A_{t} f_{t}\left(X_{1 t}, \ldots, X_{m t}\right)=A_{t}\left(\sum_{i}^{m} \lambda_{i t} X_{i t}^{\beta_{t}}\right)^{1 / \beta_{t}}
$$

where $A_{t}$ represents an index of Hicks neutral technical change. The $\lambda_{i t}$ 's are technology parameters reflecting factors efficiencies and may vary through time indicating factor $-i$ augmenting (saving) technical change and $\sum_{i} \lambda_{i t}=1$ The technology parameter $\beta_{t} \in(-\infty ; 0) \cup(0 ; 1)$ is crucial in the CES technology as it governs $\sigma_{t}$, the elasticity of substitution between the various factors, i.e. $\sigma_{t}=\frac{1}{1-\beta_{t}} \in(0 ; 1) \cup(1 ; \infty)$ and may vary over time. Note that in the CES situation, the Allen partial elasticity of substitution and the Morishima elasticity of substitution are equal to $\sigma_{t}$.

Under perfect competition in the product market, the output price $p_{t}$, used as a numeraire to factor prices, can be derived from the null profit condition:

$$
p_{t} Y_{t}-\sum_{i} p_{i t} X_{i t}=0
$$

where $p_{t} \equiv 1$ and $p_{i t}$ is the real price of factor $X_{i t}$.

Assuming perfect competition, factor markets are in equilibrium when factor prices are equal to their marginal productivity, that is:

$$
p_{i t}=\frac{\partial F_{t}}{\partial X_{i t}}=A_{t}^{\frac{\sigma_{t}-1}{\sigma_{t}}} \lambda_{i t}\left(\frac{X_{i t}}{Y_{t}}\right)^{-\frac{1}{\sigma_{t}}}
$$

Note that using factor $m$ as reference, log relative factor prices are given by:

$$
\ln \frac{p_{i t}}{p_{m t}}=\ln \frac{\lambda_{i t}}{\lambda_{m t}}-\frac{1}{\sigma_{t}} \ln \frac{X_{i t}}{X_{m t}}
$$

The system of $m-1$ equations defined by Equation 8 is usually estimated to access the parameters of the production function based on exogenous relative factor quantities and endogenous relative factor prices. Equation 8 can also be used to forecast factor prices based on the structural production parameters and forecasts of the relative factor quantities.

\footnotetext{
${ }^{9}$ Results for the Cobb-Douglas production function, a special case of the CES production function when $\sigma \rightarrow 1$, are available upon request to the author.
} 
Dupuy: Hicks Neutral Technical Change Revisited

Rearranging equation 7 , in equilibrium, factor demand reads as:

$$
X_{i t}=Y_{t}\left(\frac{\lambda_{i t}}{p_{i t}}\right)^{\sigma_{t}} A_{t}^{\sigma_{t}-1}
$$

Proposition 1 If an economy is described by a CES production function and perfect competition in the output and factor markets then Hicks neutral technical change is defined as $\ln s p_{t}-I_{\sigma_{t}}\left[\Lambda_{t} \mid \widetilde{P}_{t}\right]$ the information of order $\sigma_{t}$ obtained if the distribution of factor prices $P_{t}$ is replaced by the distribution of factor efficiency parameters $\Lambda_{t}$ where $\sigma_{t}$ is the parameter that governs the elasticity of substitution between factors of production.

Proof. Substituting equation 9 in equation 5 we obtain:

$$
\begin{aligned}
Y_{t} & =Y_{t} A_{t}\left(\sum_{i}^{n} \lambda_{i t}^{\sigma_{t}} p_{i t}^{1-\sigma_{t}} A_{t}^{\beta_{t}\left(\sigma_{t}-1\right)}\right)^{1 / \beta_{t}} \\
& \Leftrightarrow A_{t}^{\sigma_{t}}\left(\sum_{i}^{n} \lambda_{i t}^{\sigma_{t}} p_{i t}^{1-\sigma_{t}}\right)^{1 / \beta_{t}}=1
\end{aligned}
$$

I normalize real factor prices by $s p_{t}=\sum_{i} p_{i t}$ so that $\widetilde{p}_{i t}=\frac{p_{i t}}{s p_{t}}$ and $\widetilde{p}_{i t}>0 \forall i$ and $\sum_{i} \widetilde{p}_{i t}=1$. Taking the logarithmic expression of equation 11, I obtain:

$$
\begin{aligned}
\ln A_{t} & =\ln s p_{t}-\frac{1}{\sigma_{t}-1} \ln \sum_{i}^{m} \frac{\lambda_{i t}^{\sigma_{t}}}{\widetilde{p}_{i t}^{\sigma_{t}-1}} \\
& =\ln s p_{t}-I_{\sigma_{t}}\left[\Lambda_{t} \mid \widetilde{P}_{t}\right]
\end{aligned}
$$

where $\Lambda_{t}=\left\langle\lambda_{1 t}, \ldots, \lambda_{m t}\right\rangle$ and $\widetilde{P}_{t}=\left\langle\widetilde{p}_{1 t}, \ldots, \widetilde{p}_{m t}\right\rangle$.

Hence, Hicks neutral technical change in an economy described by a CES technology ${ }^{10}$ and perfect competition in the output and factors markets is equal to the (log) sum of real factor prices less the information of order $\sigma$ obtained if the distribution of normalized factor prices $\widetilde{P}_{t}$ is replaced by the distribution of efficiency parameters $\Lambda_{t}$. The parameter that governs the elasticity of substitution between factors is herewith regarded as the order of information.

In other words, Proposition 1 states that the larger the inequality between normalized real factor prices and the efficiency parameters the larger Hicks neutral technical change. Intuitively, the larger the elasticity of substitution between factors, the less uncertainty about future factor prices and therefore the more

${ }^{10}$ In the Cobb-Douglas case, one finds that $\ln A_{t}=\ln s p_{t}-I_{1}\left[\Lambda_{t} \mid \widetilde{P}_{t}\right]$. 
information is to be expected from observing differences between factor efficiencies and future factor prices.

To ease the reader on the interpretation of the elasticity of substitution as an order of information I use a special case of the CES function: namely the linear production function when $\sigma_{t} \rightarrow \infty$.

$$
Y_{t}=A_{t} \sum_{i}^{m} \lambda_{i t} X_{i t}
$$

where $\sum_{i} \lambda_{i t}=1$.

Equating the marginal productivity of each input to the respective prices, one obtains: $A_{t} \lambda_{i t}=p_{i t}=A_{t} \widetilde{p}_{i t}$. One can directly see that the linear production technology implies $I_{\sigma \rightarrow \infty}\left[\Lambda_{t} \mid \widetilde{P}_{t}\right]=0$. Hence, under infinite substitution, there is little uncertainty about future factor prices, they should be equal to input efficiencies, $A_{t}=\sum_{i} p_{i t}$.

Generalization to nested two-level CES production functions

Consider an economy where, at time $t$, identical firms produce output level $Y_{t}$ using a two-level CES technology (see Sato (1967)) containing $m$ groups of factors, each with $n_{i}$ factors, denoted $X_{i j t}$. Assume constant returns to scale and that all factors are supplied inelastically.

$$
\begin{aligned}
Y_{t}= & A_{t} f_{t}\left(G_{1 t}, \ldots, G_{m t}\right)=A_{t}\left(\sum_{i}^{m} \lambda_{i t} G_{i t}^{\beta_{t}}\right)^{1 / \beta_{t}} \\
& \text { where } \\
G_{i t}= & G_{i t}\left(X_{i 1 t}, \ldots, X_{i n_{i} t}\right)=\left(\sum_{j}^{n_{i}} \pi_{i j t} X_{i j t}^{\beta_{i t}}\right)^{1 / \beta_{i t}}
\end{aligned}
$$

where $A_{t}$ represents an index of Hicks neutral technical change. The $\lambda_{i t}$ 's are technology parameters reflecting composite factors $G_{i}$ efficiencies and may vary through time indicating composite factor $-i$ augmenting (saving) technical change and $\sum_{i} \lambda_{i t}=1, \pi_{i j t}$ 's are technology parameters reflecting factors $X_{i j}$ efficiencies and may vary through time indicating factor-ij augmenting (saving) technical change within composite group $i$ and $\sum_{j} \pi_{i j t}=1$. The technology parameter $\beta_{t} \in(-\infty ; 0) \cup(0 ; 1)$ governs $\sigma_{t}$ the parameter of elasticity of substitution between the various composite factors, i.e. $\sigma_{t}=\frac{1}{1-\beta_{t}} \in(0 ; 1) \cup(1 ; \infty)$. The technology parameter $\beta_{i t} \in(-\infty ; 0) \cup(0 ; 1)$ governs $\sigma_{i t}$, the parameter of elasticity of substitution between the various factors within composite $i$, i.e. $\sigma_{i t}=\frac{1}{1-\beta_{i t}} \in(0 ; 1) \cup(1 ; \infty)$. 


\section{Dupuy: Hicks Neutral Technical Change Revisited}

Under perfect competition in the product market, the output price $p_{t}$, used as a numeraire to factor prices, can be derived from the null profit condition:

$$
p_{t} Y_{t}-\sum_{i} \sum_{j} p_{i j t} X_{i j t}=0
$$

where $p_{t} \equiv 1$ and $p_{i j t}$ is the real price of factor $X_{i j t}$.

Assuming perfect competition, factor markets are in equilibrium when factor prices are equal to their marginal productivity, that is:

$$
p_{i j t}=\frac{\partial F}{\partial X_{i j t}}=A_{t}^{\frac{\sigma_{t}-1}{\sigma_{t}}} \lambda_{i t} \pi_{i j t}\left(\frac{X_{i j t}}{G_{i t}}\right)^{-\frac{1}{\sigma_{i t}}}\left(\frac{G_{i t}}{Y_{t}}\right)^{-\frac{1}{\sigma_{t}}}
$$

Note that using factor $m$ in composite $g$ as reference, log relative factor prices are given by:

$$
\ln \frac{p_{i j t}}{p_{g m t}}=\ln \frac{\lambda_{i t}}{\lambda_{g t}}+\ln \frac{\pi_{i j t}}{\pi_{g m t}}-\frac{1}{\sigma_{i t}} \ln \left(\frac{X_{i j t}}{G_{i t}}\right)+\frac{1}{\sigma_{g t}} \ln \left(\frac{X_{g m t}}{G_{g t}}\right)-\frac{1}{\sigma_{t}} \ln \frac{G_{i t}}{G_{g t}}
$$

Rearranging equation 17, in equilibrium, relative factor demand within composite $i$ reads as:

$$
X_{i j t}=\left(\frac{\pi_{i j t}}{\pi_{i n_{i} t}}\right)^{\sigma_{i t}}\left(\frac{p_{i j t}}{p_{i n_{i} t}}\right)^{-\sigma_{i t}} X_{i n_{i} t}
$$

Proposition 2 If an economy is described by a two-level CES production function and perfect competition in the output and factor markets then Hicks neutral technical change is defined as $\ln s p_{t}-I_{\sigma_{t}}^{*}\left[\Lambda_{t} \mid \widetilde{S P_{t}}\right]$ the weighted information of order $\sigma_{t}$ obtained if the distribution of composite prices $S P_{t}$ is replaced by the distribution of composite efficiency parameters $\Lambda_{t}$ weighted by an exponential function of the information of order $\sigma_{i t}$ obtained if within each composite $i$, the distribution of factor prices $P_{i t}$ is replaced by the distribution of factor efficiency parameters $\Pi_{t}$ where $\sigma_{t}$ and $\sigma_{i t}$ are the parameters that govern respectively the elasticity of substitution between composite and the elasticity of substitution within composite between factors of production.

Proof. Substituting equation 19 in equation 15 we obtain: 
Topics in Macroeconomics, Vol. 6 [2006], Iss. 2, Art. 2

$$
\frac{G_{i t}}{X_{i n_{i} t}}=\pi_{i n_{i} t}^{-\sigma_{i t}} p_{i i_{i} t}^{\sigma_{i t}}\left(\sum_{j}^{n_{i}} \pi_{i j t}^{\sigma_{i t}} p_{i j t}^{1-\sigma_{i t}}\right)^{\frac{\sigma_{i t}}{\sigma_{i t}-1}}
$$

Rearranging equation 17 we obtain:

$$
\frac{G_{i t}}{X_{i n_{i} t}}=A_{t}^{\frac{\beta_{t}}{\beta_{i t}-1}} \lambda_{i t}^{-\sigma_{i t}} \pi_{i n_{i} t}^{-\sigma_{i t}} p_{i i_{i} t}^{\sigma_{i t}}\left(\frac{G_{i t}}{Y_{t}}\right)^{\frac{\sigma_{i t}}{\sigma_{t}}}
$$

Substituting equation 20 in 21 and solving for $G_{i t}$ yields

$$
G_{i t}=A_{t}^{\frac{\beta_{t}}{\beta_{t}-1}} Y_{t} \lambda_{i t}^{\sigma_{t}}\left(\sum_{j}^{n_{i}} \pi_{i j t}^{\sigma_{i t}} p_{i j t}^{1-\sigma_{i t}}\right)^{\frac{\sigma_{t}}{\sigma_{i t}-1}}
$$

Finally, substituting equation 22 in equation 14 and rearranging yields:

$$
A_{t}=\left(\sum_{i}^{m} \lambda_{i t}^{\sigma_{t}}\left(\sum_{j}^{n_{i}} \pi_{i j t}^{\sigma_{i t}} p_{i j t}^{1-\sigma_{i t}}\right)^{\frac{1-\sigma_{t}}{1-\sigma_{i t}}}\right)^{\frac{1}{1-\sigma_{t}}}
$$

Once again, I normalize real factor prices within composite $i$ by $s p_{i t}=\sum_{j} p_{i j t}$ so that $\widetilde{p}_{i j t}=\frac{p_{i j t}}{s p_{i t}}$ and $\widetilde{p}_{i j t}>0 \forall i, j$ and $\sum_{j} \widetilde{p}_{i j t}=1$ and normalize $s p_{i t}$ by $s p_{t}=\sum_{i} s p_{i t}$ so that $\widetilde{s p}_{i t}=\frac{s p_{i t}}{s p_{t}}$ and $\widetilde{s p}_{i t}>0 \forall i$ and and $\sum_{j} \widetilde{p}_{i j t}=1$. Taking the logarithmic expression of equation 23 , I obtain:

$$
\begin{aligned}
\ln A_{t} & =\ln s p_{t}-\frac{1}{\sigma_{t}-1} \ln \sum_{i}^{m} \frac{\lambda_{i t}^{\sigma_{t}}}{\widetilde{s p}_{i t}^{\sigma_{t}-1}} \exp \left(\left(\sigma_{t}-1\right) I_{\sigma_{i t}}\left[\Pi_{i t} \mid \widetilde{P}_{i t}\right]\right) \\
& =\ln s p_{t}-I_{\sigma_{t}}^{*}\left[\Lambda_{t} \mid \widetilde{S P}_{t}\right]
\end{aligned}
$$

where $\Lambda_{t}=\left\langle\lambda_{1 t}, \ldots, \lambda_{n t}\right\rangle$ and $\widetilde{S P}_{t}=\left\langle\widetilde{p}_{1 t}, \ldots, \widetilde{p}_{m t}\right\rangle, \Pi_{i t}=\left\langle\pi_{i 1 t}, \ldots, \pi_{i n_{i} t}\right\rangle$ and $\widetilde{P}_{i t}=$ $\left\langle\widetilde{p}_{i 1 t}, \ldots, \widetilde{p}_{i n_{i} t}\right\rangle$.

Hence, Hicks neutral technical change in an economy described by a two level CES technology ${ }^{11}$ and perfect competition in the output and factors markets is equal to the $(\log )$ sum of real factor prices less the weighted information of order $\sigma$ obtained if the distribution of normalized composite prices $\widetilde{S P}$ is replaced by the distribution of composite efficiency parameters $\Lambda_{t}$ weighted by an exponential function of the information of order $\sigma_{i}$ obtained if within each composite $i$, the distribution of normalized factor prices $\widetilde{P_{i t}}$ is replaced by the distribution of factor efficiency parameters $\Pi_{t}$. The parameters that governs the elasticity of substitution between composites and within composite between factors are herewith regarded as the respective orders of information.

\footnotetext{
${ }^{11}$ In the Cobb-Douglas case, one finds that $\ln A_{t}=\ln s p_{t}-I_{1}^{*}\left[\Lambda_{t} \mid \widetilde{S P_{t}}\right]$.
} 
Dupuy: Hicks Neutral Technical Change Revisited

An intuitive interpretation of the information measure of Hicks neutral technical change and the elasticity of substitution

Suppose an econometrician wants to estimate the production function $F$. She has $N$ observations on relative factor quantities and prices. Applying an appropriate econometric methodology she estimates the technological parameters of the production function (a Nested CES for instance) from the system of $\left(\sum_{i} n_{i}\right)-1$ equations 18. The next year, the econometrician gets a $N+1^{\text {th }}$ observation of relative quantities and prices and wants to know whether this new observation fits with the previous data (appears as if generated through the production function she estimated last year). The information measure tells exactly this to the econometrician. If new prices are too far from the vector of efficiency parameters estimated with the first $N$ observations, then the information content of the message embodied in the $N+1^{\text {th }}$ observation is large which indicates a large "stock of ideas" $A(t)$. If the "distance" between the new price vector and the efficiency parameters is larger than the distance between the previous price vector and the efficiency parameters, then technical change has positively contributed to output growth, i.e. $A(t)>A(t-1)$. In this information context, the interpretation of the elasticity of substitution between the various input factors is straightforward. The larger the elasticity of substitution the more surprised the econometrician should be at observing the vector of factor prices of the new observation diverging from the efficiency parameters estimated on the previous $N$ observations. Actually, in the case of infinite elasticity of substitution, linear production function, factor prices are independent of factor quantities and equal to the respective factor efficiency parameters. Taken from an information perspective, this means that the larger $\sigma$, the less uncertainty there is today regarding future prices. The less uncertainty there is today, the more information is to be expected when we actually observe future factor prices diverging from the respective efficiency parameters.

\section{Implications}

\section{Estimation}

Using real data, the traditional growth accounting method proposed by Solow (1957), and the information of order $\sigma$ method may, and as I shall show below do provide different results. To illustrate the differences in productivity measures as derived from both methods I propose to estimate technical change for the US economy in the period 1948-1999 using both methods and compare the results. The data I use are from Jorgenson (2001) and consist of time-series of nominal prices and values of non IT capital services, IT capital services and labor services as well as series of prices and values of gross domestic product and gross domestic income. Price series are normalized to 1 in 1996. 
The growth accounting method to predict ex post technical change consists of computing the following Tornqvist index (a discrete time approximation to the Divisia index):

$$
S R_{t}=\Delta \ln Y_{t}-\widetilde{\alpha}_{I T, t} \Delta \ln I T_{t}-\widetilde{\alpha}_{N I T, t} \Delta \ln N I T_{t}-\widetilde{\alpha}_{L, t} \Delta \ln L_{t}
$$

where $\widetilde{\alpha}_{i, t}=\frac{\alpha_{i, t}+\alpha_{i, t-1}}{2}$ and $\alpha_{i, t}$ is the share of factor $i$ in total revenue at time $t$.

The information method to predict ex post Hicks neutral technical change requires the estimation of a two-level CES production function. The estimation of the structural parameters of the production function is conditional on how the various factors of production are nested. There are four ways to nest the three factors: i) all in a different nest which implies a one level CES production function, ii) $(I T, N I T)-L$, iii) $(I T, L)-N I T$ and iv $)(N I T, L)-I T$. The choice for the nest however should be supported by the data rather than imposed ex ante. Therefore, to evaluate the extent to which a two-level CES production is supported by the data and which nest seems appropriate, I first test for the separability of the various factors in production. The procedure is standard and was proposed by Berndt and Christensen (1973;1974) and extended by Denny and Fuss (1977). The procedure consists to:

1. estimate the parameters of a translog cost function, applying the Zellner efficient estimation technique on the following system of cost shares of labor and non-IT factors ${ }^{12} \alpha_{i t}=\omega_{i}+\sum_{j} \omega_{i j} \ln p_{j}+\omega_{i t} t$ where $i=L, N I T$ and $j=L, N I T, I T$ and,

2. test the null hypothesis of weak separability of factor say 3 of the type $(1,2)-3$ by testing the nonlinear restriction $\omega_{1} \omega_{23}-\omega_{2} \omega_{13}=0$.

While the null hypothesis of weak separability is rejected at $1 \%$ for labor $\left(\chi_{1}^{2}=\right.$ $32.9)$ and at $10 \%$ for $I T\left(\chi_{1}^{2}=3.3\right)$ it cannot be rejected for $N o n-I T\left(\chi_{1}^{2}=0.5\right)$. The results of these tests indicate that a nest of labor with $I T$ is supported by the data. A two-level CES production function with nest specification iii) is therefore estimated. All parameters of interests are identified ${ }^{13}$ in the system of 2 equations defined by Equation 18.

\footnotetext{
${ }^{12}$ The parameters of the third share equation $\omega_{3}$ are derived from the parameters estimates of the two other share equations together with the linear homogeneity restrictions imposed on the implicit production function.

${ }^{13}$ Note that the structural parameters of the production function, i.e. $\sigma_{t}, \sigma_{i t}, \lambda_{i t}$ and $\pi_{i j t}$, may not be constant through the period 1948-1999. To account for the possibility of a structural break of unknown timing in the system of equations 18, I ran the Quandt statistic on the span 1948-1999, allowing for a standard trimming of $5 \%$ to prevents end-of-sample problems, for all possible ways to nest factors. For all production functions, there is strong statistical evidence of a structural break, most likely in 1974 . Note that the trimming of $5 \%$ neccessary to overcome problems in dealing with end-of-sample breaks does not allow me to test for a structural break in 1995 as recently reported by Khan and Rich (2003).
} 
Dupuy: Hicks Neutral Technical Change Revisited

$$
\begin{aligned}
\ln \frac{p_{I T t}}{p_{L t}}= & \ln \frac{\pi_{I T t}}{1-\pi_{I T t}}-\frac{1}{\sigma_{1}+\sigma_{1}^{T} D_{T}} \ln \frac{I T_{t}}{\widetilde{L}_{t}} \\
\ln \frac{p_{N I T t}}{p_{L t}}= & \ln \frac{\lambda_{N I T t}}{1-\lambda_{N I T t}}-\ln \pi_{L t}-\frac{1}{\sigma+\sigma^{T} D_{T}} \ln N I T_{t}+ \\
& \frac{1}{\sigma_{1}+\sigma_{1}^{T} D_{T}} \ln \widetilde{L}_{t}+\left(\frac{1}{\sigma+\sigma^{T} D_{T}}-\frac{1}{\sigma_{1}+\sigma_{1}^{T} D_{T}}\right) \ln G_{1}
\end{aligned}
$$

where, $\pi_{I T t}=\frac{\exp \left(a_{I T}+b_{I T} \times t+b_{I T}^{T} \times t \times D_{T}\right)}{\left(1+\exp \left(a_{I T}+b_{I T} \times t+b_{I T}^{T} \times t \times D_{T}\right)\right)}, G_{1}=\left(\pi_{I T t} I T_{t}^{\beta_{1 T}}+\pi_{L t} \widetilde{L}_{t}^{\beta_{1 T}}\right)^{1 / \beta_{1 T}}$, $\beta_{1 T}=\frac{\sigma_{1}+\sigma_{1}^{T} D_{T}-1}{\sigma_{1}+\sigma_{1}^{T} D_{T}}$ and $\lambda_{N I T t}=\frac{\exp \left(a_{N I T}+b_{N I T} \times t+b_{N I T}^{T} \times t \times D_{T}\right)}{1+\exp \left(a_{N I T}+b_{N I T} \times t+b_{N I T}^{T} \times t \times D_{T}\right)}$. Note that $\widetilde{L}_{t}$ is the instrumented labor services series and, $D_{T}=1$ if $t>T, D_{T}=0$ otherwise.

This system of nonlinear equations can be estimated using Full Information Maximum Likelihood estimation techniques. ${ }^{14}$ Moreover, as Krusell et al. (2000), to allow for the possible endogeneity of labor (dependence of hours worked on shocks), I use a two stage procedure. In the first step, treating labor as endogenous, I project labor onto a constant, a trend, current and lagged IT and non IT capital services and the lagged relative price of IT to non IT services. In the second step, I derive the FIML estimates of the system replacing labor by its instrumented series. Moreover, the structural parameters are allowed to vary over time. The efficiency parameters may follow a trend and shift after year $T$ whereas the substitution parameters may shift after year $T$.

Estimation results ${ }^{15}$ are presented in Table 1. The Quandt statistic (sup of Likelihood Ratio) - a test for the presence of a structural break in the trend and elasticity parameters at unknown date- is significant at 1\% ( $\sup -L R=29.97$ is larger than 20.71, the critical value for $p=4, \pi_{0}=0.15$, provided in Table I in Andrews (1993 )) and indicates a structural break in 1974. The estimated elasticity of substitution parameter between IT capital services and labor services is 0.99 and the elasticity of substitution parameter between non IT capital services and labor services is 0.74 , which is consistent with previous estimates in the literature (see Hamermesh (1993) for a review), and indicate gross complementarity between the three factors. Note also that while there is no significant evidence of non IT capital services augmenting technical change relative to the IT capital services and labor services mix, there is a strong significant evidence for IT capital services augmenting technical change relative to labor services at a 5.5 percent per year between 1948 and 1973 and a significant decrease to an yearly rate of 4.8 after 1973 .

\footnotetext{
${ }^{14}$ Judge et al. (1985) Section 15.7.2.

${ }^{15}$ Note that the nest $F(N I T, G(I T$, Labor $))$ provides the largest (log) likelihood, 6.85 (compared with 6.77 for $F($ Labor, $G(I T, N I T))$ and 5.15 for $F(I T, G(N I T$, Labor $)))$.
} 
Using these estimates of $\sigma_{t}, \sigma_{i t}, \lambda_{i t}$ and $\pi_{i j t}$, Hicks neutral technical change can then be calculated as:

$$
\ln A_{I n f o, t}=-\frac{1}{\widehat{\sigma}-1} \ln \left(\frac{\widehat{\lambda}_{N I T t}^{\widehat{\sigma}}}{p_{N I T t}^{\widehat{\sigma}-1}}+\left(1-\widehat{\lambda}_{N I T t}\right)^{\widehat{\sigma}}\left(\frac{\widehat{\pi}_{I T t}^{\widehat{\sigma}_{i}}}{p_{I T t}^{\widehat{\sigma}_{i}-1}}+\frac{\widehat{\pi}_{L t}^{\widehat{\sigma}_{i}}}{p_{L t}^{\widehat{\sigma}_{i}-1}}\right)^{\frac{1-\widehat{\sigma}}{1-\widehat{\sigma}_{1}}}\right)
$$

where $p_{i j t}$ is the real price of factor $i j$, i.e. the series of nominal factor prices deflated by the series of gross domestic product price. Hats refer to parameters' estimates (see Table 1).

The contribution of non neutral technical change in productivity growth can now be derived as the difference between $S R$ and the growth rate of $A_{\text {Info }}$, i.e. $\frac{\partial f / \partial t}{f}=S R-\frac{\dot{A}_{I n f_{0}}}{A_{\text {Info }}}$. As shown in Table $2, S R$ grew in average at a yearly rate of 0.64 percent between 1948 and 1999 whereas Hicks neutral technical change measured by the information method grew 0.17 percentage points faster. Non neutral technical changes therefore have contributed to slow output growth. The faster growth of technical change measured by the information method compared to the growth accounting method actually occurs after 1973 and remains roughly constant at 0.45 percentage points through 1999. Interestingly enough while the ex post predictions of $S R$ indicate a drop of 0.76 percentage points in total factor productivity growth between 1948-1973 and 1973-1990, the drop predicted by the information measure is limited to 0.17 percentage points. This means that the deceleration of the contribution of non neutral technical changes is responsible for $3 / 4^{t h}$ of the productivity slowdown after 1973 . The productivity slowdown observed in the $70 \mathrm{~s}$ and $80 \mathrm{~s}$ is therefore merely due to a deceleration in the contribution of non neutral technical changes.

The question arises: Is non neutral technical change significant? To answer this question, I note that under the null hypothesis that the productivity changes captured by $S R$ are merely neutral, the information measure and $S R$ should be identical. Therefore to test the importance of non neutral technical change I regress Solow's residual on the information measure and a constant. Under the null hypothesis of the absence of non neutral technical change, the slope should be equal to unity and the constant equal to 0 (and the $R^{2}$ should be equal to one). The results of this regression, reported in the last part of Table 2, clearly indicate that the null hypothesis is rejected. The $F$ statistic for the joint hypothesis of constant is zero and slope is unity is rejected not only for the whole period but also in every subperiods. These results provide strong empirical evidence that both types of technical changes have occurred simultaneously in the US throughout the span 1948-1999. Interesting enough, except for the period 1948-1973, the slope is not significantly different from unity indicating that the growth rate 


\section{Dupuy: Hicks Neutral Technical Change Revisited}

differential between neutral and non neutral technical change is constant within the subperiods distinguished after 1973.

\section{Robustness checks}

Although $S R$ and the information measure of Hicks neutral technical change properly measure technical changes under perfect competition, constant returns to scale and in the absence of measurement errors in factor prices, as soon as the conditions met in the output and factor markets diverge from the competition conditions or in the presence of measurement errors, the relationship between marginal productivity of factors of production and their prices is altered as well as the relationship between marginal cost and output price. Imperfect competition and measurement errors ${ }^{16}$ alter the distribution of income among the various inputs so that the income share of each input $V_{X_{i}}$ diverges from the respective factor elasticity, i.e. $V_{X_{i}}=E_{Y X_{i}}+e_{X_{i}} \lessgtr E_{Y X_{i}}$ with $\sum_{i} V_{X_{i}}=\sum_{i} E_{Y X_{i}}=1 .{ }^{17}$ Under imperfect competition $e_{X_{i}}$ would be larger than 0 for factors that are rewarded more than their marginal contribution to production, $p_{X_{i}}=\frac{\partial F}{\partial X_{i}}+\varepsilon_{X_{i}}$ with $e_{X_{i}}=\frac{\varepsilon_{X_{i}} X_{i}}{Y}$ so that $V_{X_{i}}=\frac{p_{X_{i}} X_{i}}{Y}=\frac{\frac{\partial F}{\partial X_{i}} X_{i}}{Y}+e_{X_{i}}=E_{Y X_{i}}+e_{X_{i}}{ }^{18}$ Errors $e_{X_{i}}$ larger than 0 could also indicate that the price of factor $X_{i}$ is overestimated. Since the calculation of $S R$ consists to proxy the output elasticities by the respective income shares, this yields $\widehat{S R}=\frac{\dot{Y}}{Y}-\sum_{i} V_{X_{i}} \frac{\dot{X}_{i}}{X_{i}}=S R-\sum_{i} e_{X_{i}} \frac{\dot{X}_{i}}{X_{i}}$ where $\widehat{S R}$ is the Solow residual as measured from data on income shares and $S R$ is the true Solow residual. The term $\sum_{i} e_{X_{i}} \frac{\dot{X}_{i}}{X_{i}}$ represents the bias that arises when the econometrician uses data on income shares to proxy output elasticities under either imperfect competition or measurement errors in factors prices. ${ }^{19}$ Similarly, the information measure of Hicks neutral technical change as derived from real factor prices will be biased as soon as $\varepsilon_{X_{i}} \neq 0$ for some $X_{i}$.

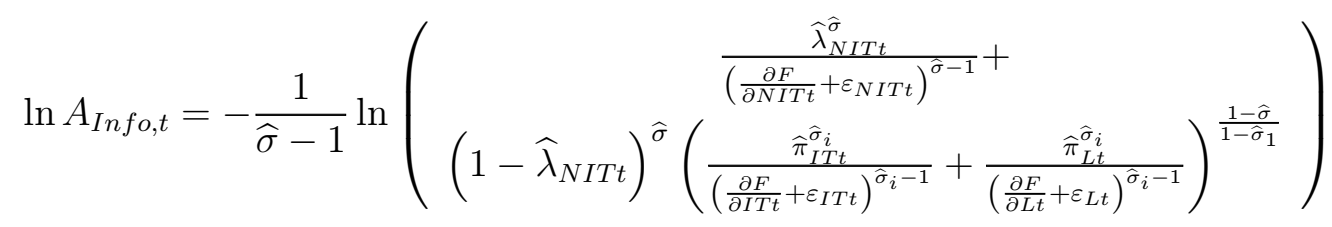

This means that, following Hall's (1988) methodology, under imperfect compe-

\footnotetext{
${ }^{16}$ Assuming constant returns to scale the output elasticities sum to unity, $\sum_{i} E_{Y X_{i}}=1$.

${ }^{17}$ See Gordon (2004) for a similar exposition.

${ }^{18}$ Note that $p_{X_{i}}$ are real factor prices.

${ }^{19}$ This bias is negligible when the various inputs grow at the same rate under constant returns to scale, i.e. $\sum_{i} e_{X_{i}}=0$ so that $\widehat{S R}=S R$. Hence, the magnitude of the bias will be larger in periods where inputs grow at very different rates. Data for the US indicate that labor services and IT services increased constantly at a respective yearly rate of 2 and 15 percent whereas non-IT services increased at a yearly rate of 4.4 percent through 1973 and 2.8 percent thereafter. Clearly, if markets are less than perfectly competitive or factor prices are measured with errors then $S R$ will be significantly biased as the various factors grow at very different rates.
} 
tition or measurement errors, the covariance of $S R$ with an instrumental variable correlated with the growth of inputs $\frac{\dot{X}_{i}}{X_{i}}$ will differ from zero because of the terms $e_{X_{i}}$. Similarly, the information measure will be correlated with the instrument since prices will diverge from marginal productivity, i.e. by $\varepsilon_{X_{i}}$. To investigate the possibility of imperfect competition or measurement errors in the data, I analyze the content of both measures of technical change following Hall (1988). Hall (1988) proposed a simple test for the null hypothesis of perfect competition and constant returns to scale. Under the null hypothesis of perfect competition and constant returns to scale, a method that measures productivity is uncorrelated with all variables known neither to be causes of productivity shifts nor to be caused by productivity shifts. Rejecting the null hypothesis will indicate either imperfect competition or non constant returns to scale. In his empirical test, Hall (1988) used the rate of growth of military spending in real terms, the world price of crude petroleum in dollars and the political party of the president as instruments. The formal test consists of computing a measure of technical change $(S R$ and the information measure) and regress this measure against the instrument chosen.

$$
\begin{aligned}
S R & =\delta_{\text {Solow }, 0}+\delta_{\text {Solow }, 1} \Delta \ln \text { Instrument }_{t}+e_{\text {Solow }, t} \\
\Delta \ln A_{\text {Info }, t} & =\delta_{\text {Info }, 0}+\delta_{\text {Info }, 1} \Delta \ln \text { Instrument }_{t}+e_{\text {Info }, t}
\end{aligned}
$$

Under the null hypothesis of perfect competition and constant return to scale, a method that measures productivity will have $\delta_{1}=0$. Hence if Solow's residual and the information method measure productivity, under the null hypothesis the parameters $\delta_{\text {Solow }, 1}$ or $\delta_{\text {Info, } 1}$ should be equal to 0 . However, if $\delta_{1}$ is found significantly different from 0 , this means either that market conditions differ from perfect competition or constant returns to scale. However, if there is less than perfect competition and non constant returns to scale then the test will reject the null hypothesis for all possible productivity measures.

In this paper I use the rate of growth in military expenditures in real terms (deflated by GDP price), the rate of growth in world price of crude petroleum in dollars and the political party of the president as instruments. Using real military expenditures, I did not find significant evidence against the null hypothesis, i.e. $\delta_{\text {Solow }, 1}=2.25$ with marginal significance level for one-tailed test is 0.19 and $\delta_{\text {Info }, 1}=-1.46$ with marginal significance level 0.31 nor with the political party of the president i.e. $\delta_{\text {Solow, } 1}=0.02$ with marginal significance level for one-tailed test is 0.50 and $\delta_{\text {Info, } 1}=-0.19$ with marginal significance level 0.50 . However, using world oil price as instruments, I found some significant evidence at $5 \%$ against the null hypothesis for the Solow residual, ${ }^{20}$ i.e. $\delta_{\text {Solow }, 1}=2.25(0.05)$ but

\footnotetext{
${ }^{20}$ Investigating Solow's residual, Hall (1988) found strong significant evidence for rejecting the null hypothesis of competition and constant returns to scale using oil prices but non with the two other instruments.
} 
Dupuy: Hicks Neutral Technical Change Revisited

not for the information method, i.e. $\delta_{\text {Info }, 1}=1.75(0.14)$. While some evidence of correlation between $S R$ and oil price is found, the information measure of neutral technical change correlates with none of the instruments. This results suggests either that there is imperfect competition or measurement errors but the three instruments used in this paper are not the one that could reveal it from the data or that there is not significant evidence of departures from perfect competition or the presence of measurement errors.

It is important to note however that, unless one is willing to argue that the market structure or measurement errors have changed dramatically over time the drop in $S R$ after 1973 is merely due to technical change and not market structure or measurement errors as the various factors grew at a roughly constant rate before and after 1973. To show this, note that since inputs grew roughly constantly over the period 1948-1999, the difference in $S R$ before and after 1973 can be written as:

$$
\begin{aligned}
\widehat{S R}_{90}-\widehat{S R}_{73} & =S R_{90}-S R_{73}-\left(\left(\sum_{i} e_{X_{i}} \frac{\dot{X}_{i}}{X_{i}}\right)_{90}-\left(\sum_{i} e_{X_{i}} \frac{\dot{X}_{i}}{X_{i}}\right)_{73}\right) \\
& \simeq S R_{90}-S R_{73}-\sum_{i} \Delta e_{X_{i}} \frac{\dot{X}_{i}}{X_{i}}
\end{aligned}
$$

where $\widehat{S R}_{73}$ and $\widehat{S R}_{90}$ are the measured Solow residuals for the period 1948-1973 and 1973-1990, $S R_{90}$ and $S R_{73}$ are the true productivity growth in the respective periods and $\Delta e_{X_{i}}$ is the difference in the average errors in measuring the share of factor $X_{i}$ between the respective periods.

Hence, unless measurement errors or the market structure have changed over time $\left(\Delta e_{X_{i}} \neq 0\right)$ the productivity slowdown measured by $S R$ reflects a true productivity slowdown. Plugging the calculated figures of $\widehat{S R}$ and the average growth rate of each input into equation 29 yields $0.76=15 \Delta e_{I T}+2 \Delta e_{L}+3.5 \Delta e_{N I T}$ with $\sum \Delta e_{X_{i}}=0$. Once rearranged and simplified this yields an expression of the change in the errors for $I T$ as a function of the change in the errors of $L$ : $\Delta e_{I T}=0.07+0.13 \Delta e_{L}$. The required change in the errors of IT increases with the change in the errors of $L$. Giving the alternative hypothesis of the drop in $S R$ its best shot, I therefore assume that the share of labor systematically overstates the output elasticity in the first period and systematically understates output elasticity after 1973, so that the magnitude of change in errors is the largest and $\Delta e_{L}<0$. Even when the share of labor diverges by as much as $10 \%$ from its output elasticity, i.e. the share overstates the elasticity by $5 \%$ before 1973 and understates the elasticity by $5 \%$ after 1973 so that $\Delta e_{L}=-0.0275-0.0275,{ }^{21}$

${ }^{21}$ The share of labor services varies around 55 percent between 1948 and 1999. 
or equivalently when the price of labor services diverge by $10 \%$ from the marginal productivity of labor, the required change in the errors of IT is as large as 0.063 . Since the share of IT services increases from an average of 1 percent before 1973 to 3 percent after 1973, this means for instance that the share of IT services understates the output elasticity of IT services by 100 percent before $1973\left(e_{I T}=-0.010\right)$ and overstates the output elasticity by 180 percent after $1973\left(e_{I T}=0.053\right) .{ }^{22}$ This exercise illustrates that the magnitude of the drop in $S R$ can only be reproduced under tremendous changes in the magnitude of the bias introduced in factor prices and therefore provides evidence in favor of a technical change explanation of the $S R$ slowdown after 1973.

\section{Conclusion}

This paper provides an alternative interpretation of Hicks neutral technical change building on the dual approach to growth accounting exposed by Jorgenson and Griliches (1967) and Shapiro (1987). Using a general nested CES production function with elasticity parameter $\sigma$, Hicks neutral technical change is identified as the information of order $\sigma$ obtained if the distribution of factor prices is replaced by the distribution of factor efficiency parameters. Together with Solow's residual, the information method enables us to distinguish between the neutral $\frac{\dot{A}}{A}$ and non neutral $\frac{\partial f / \partial t}{f}$ part of technical and organizational changes. Using Jorgenson's (2001) US data for the period 1948-1999, I estimate the structural parameters of the model allowing for technical change to be neutral and non neutral in Hicksian sense.

The main results of the paper are that i) both neutral and non neutral technical change have occurred in the US in the period 1948-1999 and ii) $3 / 4^{\text {th }}$ of the productivity slowdown observed in the 70s and 80 s is due to a deceleration in the contribution of non neutral technical changes.

Empirical result ii) is in sharp contrast with the standard assumption in output growth models that technical changes are merely captured by changes in the stock of ideas or knowledge $A(t)$ and neglecting the possibility that technical and organizational changes might also affect the marginal rate of substitution between input factors. The evidence shown in this paper indicates that the major investments in computer and information-processing equipment made after 1973 did contribute to maintain the growth of the stock of ideas at its previous

\footnotetext{
${ }^{22}$ Note that this exercise can be replicated allowing for only a share of the drop in $S R$ to be attributed to the alternative hypothesis. If for instance, only 25 percent of the drop is allowed to be caused be either changes in the market structure or measurement errors, so that $\Delta e_{I T}=0.017+0.13 \Delta e_{L}$. When the share of labor diverges by as much as $10 \%$ from its output elasticity, this requires a change of magnitude 0.01 in the errors of $e_{I T}$. This means that the share of IT services understates the output elasticity of IT services by for instance 20 percent before $1973\left(e_{I T}=-0.002\right)$ and overstates the output elasticity by 27 percent after $1973\left(e_{I T}=0.008\right)$.
} 
Dupuy: Hicks Neutral Technical Change Revisited

rate (no productivity paradox) but also changed the marginal rate of substitution between factors of production so that productivity slowed down.

\section{References}

Abramovitz, M. (1956): "Resource and Output Trends in the US Since 1870," American Economic Review, Papers and Proceedings, 46(2), 5-23.

Aiyar, S., And C.-J. DalgaARd (2004): "Total Factor Productivity Revisited: A Dual Approach to Development Accounting," EPRU Working Paper Series 04-07, Economic Policy Research Unit (EPRU), University of Copenhagen. Institute of Economics.

Allen, R. (1938): Mathematical Analysis for Economists. London: Macmillan.

Andrews, D. (1993): "Tests for Parameter Instability and Structural Change with Unknown Change Point," Econometrica, 61(4), 821-56.

Baily, M. N., and R. Grodon (1988): "The Productivity Slowdown, Measurement Issues, and the Explosion of Computer Power," Brookings Papers on Economic Activity, 2.

Berndt, E., And L. Christensen (1973): "The Translog Function and the Substitution of Equipment, Structures, and Labor in U.S. Manufacturing 192968," Journal of Econometrics, 1(1), 81-114.

(1974): "Testing for the Existence of an Aggregate Index Labor Input," American Economic Review, 64(3), 391-404.

Blackorby, C., and R. Russel (1989): "Will the Real Elasticity of Substitution Please Stand Up? (A Comparison of the Allen/Uzawa and Miroshima Elasticities)," American Economic Review, 79(4), 882-88.

Castro, R., and D. Coen-Pirani (2005): "Why Have Aggregate Skilled Hours Become So Cyclical Since the Mid1980's?," Working Paper.

De La Grandville, O. (1989): "In Quest of the Slutsky Diamond," American Economic Review, 79(3), 468-81.

Denny, M., And M. Fuss (1977): "The Use of Approximation Analysis to Test for Separability and the Existence of Consistent Aggregates," American Economic Review, 67(3), 404-418.

Dupuy, A., And A. DE Grip (2006): "Elasticity of Substitution and Productivity, Capital and Skill Intensity Differences Across Firms," Economics Letters, 90(3), 340-7. 
Topics in Macroeconomics, Vol. 6 [2006], Iss. 2, Art. 2

Dupuy, A., And P. Marey (2004): "Shifts and Twists in the Relative Productivity of Skilled Labor: Reconciling Accelerated SBTC with the Productivity Slowdown," Discussion Paper 118, Econometric Society.

Gordon, R. J. (2004): Productivity Growth, Inflation, and Unemployment. Cambridge University Press.

Griliches, Z. (1996): "The Discovery of the Residual: A Historical Note," Journal of Economic Literature, 34(3), 1324-30.

Hall, R. (1988): "The Relation Between Price and Marginal Cost in U.S. Industry," Journal of Political Economy, 96, 921-47.

Hamermesh, D. (1993): Labor Demand. Princeton, New Jersey: Princeton University Press.

Hicks, J. (1932): The Theory of Wages. London: Macmillan, 1st edn.

- (1970): "Elasticity of Substitution Again: Substitutes and Complements," Oxford Economic Papers, 22(3), 289-96.

Hsien, C.-T. (1999): "Productivity Growth and Factor Prices in East Asia," American Economic Review, Papers and Proceedings, 89(2), 133-8.

Jones, C. (1999): "Growth: With or Without Scale Effects?" American Economic Review, 89(2), 139-44.

Jorgenson, D. (2001): "Information Technology and the US Economy," American Economic Review, 91(1), 1-32.

Jorgenson, D. W., And Z. Griliches (1967): "The Explanation of Productivity Change," Review of Economic Studies, 34(3), 249-83.

Jorgenson, D. W., And K. J. Stiroh (2000): "US Economic Growth at the Industry Level," American Economic Review, Papers and Proceedings, 90(2), $161-7$.

Judge, G., W. Griffiths, R. Hill, H. Lütkepohl, and T.-C. Lee (1985): The Theory and Practice of Econometrics. New York: Wiley, 2nd edn.

Klump, R., and O. De La Grandville (2000): "Economic Growth and the Elasticity of Substitution: Two Theorems and Some Suggestions," American Economic Review, 90(1), 282-91.

Krusell, P., L. Ohanian, J.-V. Ríos-Rull, and G. Violante (2000): "Capital-Skill Complementarity and Inequality: A Macroeconomic Analysis," Econometrica, 68(5), 1029-53. 
Dupuy: Hicks Neutral Technical Change Revisited

Oliner, S. D., And D. E. Sichel (2000): "The Resurgence of Growth in the Late 1990s: Is Information Technology the Story?," Journal of Economic Perspectives, 14(4), 3-22.

Papageorgiou, C., and M. SaAm (2005): "Two-Level CES Production Technology in the Solow and Diamond Growth Models," Discussion Paper 2005-07, Department of Economics, Louisiana State University.

Renyi, A. (1961): "On Measures of Entropy and Information," Proceedings 4th Berkley Symposium on Mathematical Statistics and Probability, 1, 547-61.

Romer, P. (1990): "Endogenous Technological Change," Journal of Political Economy, 98(5), S71-S102.

SAto, K. (1967): "A Two-Level CES Production Function," Review of Economic Studies, 34, 201-18.

Sato, R., and T. Koizumi (1973): "On the Elasticities of Substitution and Complementarity," Oxford Economic Papers, 25, 44-56.

Shannon, C., And W. Weaver (1949): The Mathematical Theory of Communication. University of Illinois Press, Urbana.

Shapiro, M. D. (1987): "Are Cyclical Fluctuation in Productivity Due More to Supply Shocks or Demand Shocks?," American Economic Review, Papers and Proceedings, 77(2), 118-24.

Sichel, D. E. (1997): "The Productivity Slowdown: Is Growing Unmeasurable Sector the Culprit?," Review of Economics and Statistics, 79(3), 367-70.

Solow, R. M. (1957): "Technical Change and the Aggregate Production Function," Review of Economics and Statistics, 39(3), 312-20.

Straathof, B. (2005): "Shanon's Entropy as an Index of Product Variety," mimeo.

Theil, H. (1965): "The Information Approach to Demand Analysis," Econometrica, 33(1), 67-87.

(1967): Economics and Information Theory, vol. 7 of Studies in Mathematical and Managerial Economics. North-Holland: Amsterdam. 
Topics in Macroeconomics, Vol. 6 [2006], Iss. 2, Art. 2

Table 1: Structural parameters estimates using two-stage Full Information Maximum Likelihood estimation $(\mathrm{N}=51)$.

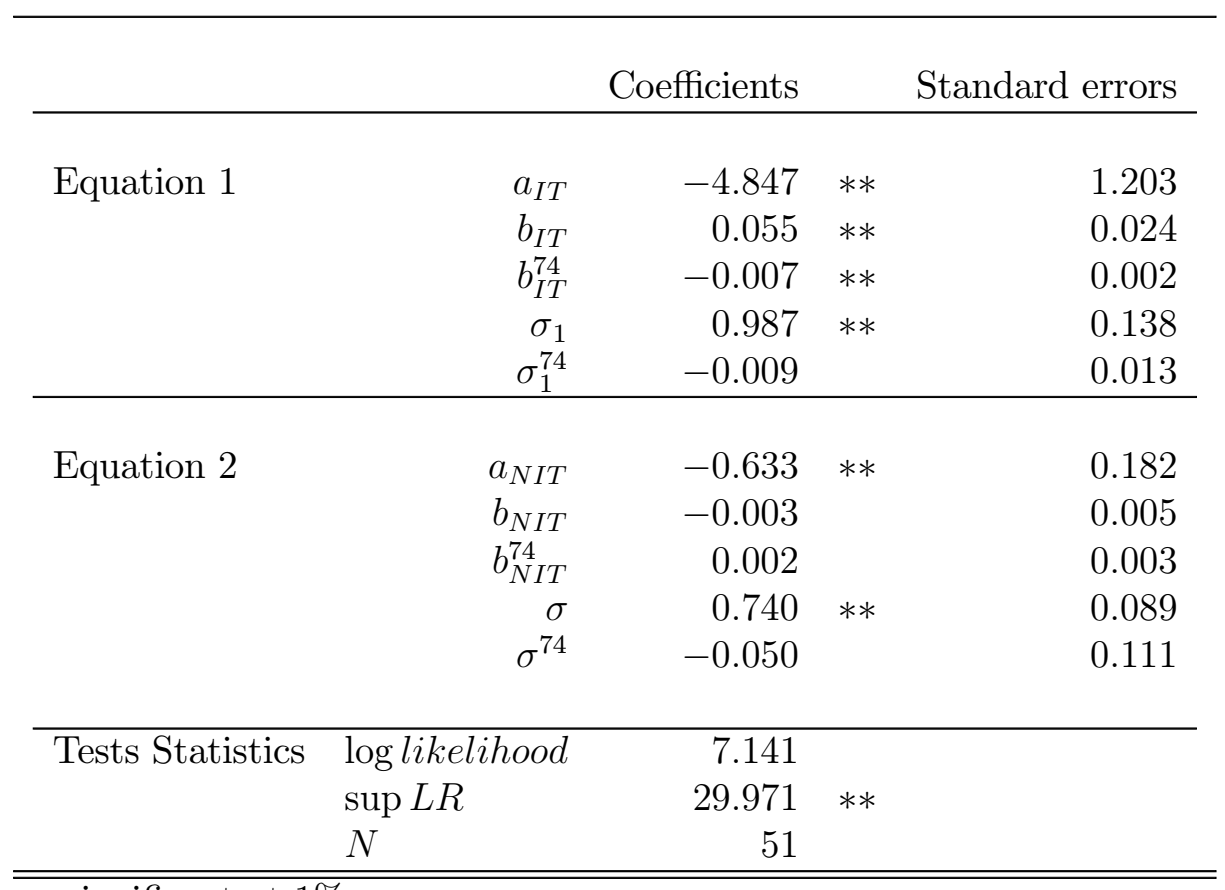

** significant at $1 \%$

Note that: $\widetilde{L}_{t}$ is the instrumented labor services series and, $D_{74}=1$ if $t>1974, D_{74}=0$ otherwise.

Equation 1: $\ln \frac{p_{I T t}}{p_{L t}}=\ln \frac{\pi_{I T t}}{1-\pi_{I T t}}-\frac{1}{\sigma_{1}+\sigma_{1}^{74} D_{74}} \ln \frac{I T_{t}}{\widetilde{L}_{t}}$ where, $\pi_{I T t}=\frac{\exp \left(a_{I T}+b_{I T} \times t+b_{I T}^{74} \times t \times D_{74}\right)}{\left(1+\exp \left(a_{I T}+b_{I T} \times t+b_{I T}^{74} \times t \times D_{74}\right)\right)}$

Equation 2: $\begin{aligned} & \ln \frac{p_{N I T t}}{p_{L t}}=\ln \frac{\lambda_{\text {NITt }}}{1-\lambda_{N I T t}}-\ln \pi_{L t}-\frac{1}{\sigma+\sigma^{74} D_{74}} \ln N I T_{t} \\ & +\frac{1}{\sigma_{1}+\sigma_{1}^{74} D_{74}} \ln \widetilde{L}_{t}+\left(\frac{1}{\sigma+\sigma^{74} D_{74}}-\frac{1}{\sigma_{1}+\sigma_{1}^{74} D_{74}}\right) \ln G_{1}\end{aligned} \quad$ where, $G_{1}=\left(\pi_{I T t} I T_{t}^{\beta_{1}}+\pi_{L t} \widetilde{L}_{t}^{\beta_{1}}\right)^{1 / \beta_{1}}$

and $\beta_{1}=\frac{\sigma_{1}+\sigma_{1}^{74} D_{74}-1}{\sigma_{1}+\sigma_{1}^{74} D_{74}}$ and $\lambda_{N I T t}=\frac{\exp \left(a_{N I T}+b_{N I T} \times t+b_{N I T}^{74} \times t \times D_{74}\right)}{1+\exp \left(a_{N I T}+b_{N I T} \times t+b_{N I T}^{74} \times t \times D_{74}\right)}$ 
Dupuy: Hicks Neutral Technical Change Revisited

Table 2: Sources of US Gross Domestic Product Growth: neutral and non neutral technical change.

\begin{tabular}{|c|c|c|c|c|c|}
\hline & 1948-1999 & $1948-1973$ & $1973-1990$ & $1990-1995$ & 1995-1999 \\
\hline Gross Domestic Product & 3.46 & 4.02 & 2.82 & 2.41 & 3.96 \\
\hline \multicolumn{6}{|l|}{ Contribution of: } \\
\hline Information technology capital services & 0.34 & 0.16 & 0.40 & 0.48 & 0.99 \\
\hline Noninformation technology capital services & 1.35 & 1.76 & 1.04 & 0.68 & 0.94 \\
\hline Labor services & 1.13 & 1.11 & 1.16 & 0.99 & 1.30 \\
\hline Technical change, Solow's residual: $S R$ & 0.64 & 0.98 & 0.22 & 0.25 & 0.74 \\
\hline Neutral: Hicks neutral Information of order $\sigma: \frac{\dot{A}_{I n f o}}{A_{I n f o}}$ & 0.81 & 0.86 & 0.69 & 0.61 & 1.19 \\
\hline Non neutral: $S R-\frac{\dot{A}_{I n f o}}{A_{\text {Info }}}=\frac{\partial f / \partial t}{f}$ & -0.17 & 0.12 & -0.47 & -0.36 & -0.45 \\
\hline
\end{tabular}

Regression

$\Delta \ln A_{\text {Solow }}=\lambda_{1}+\lambda_{2} \Delta \ln A_{\text {Info }}+e$

$$
F_{2, N-2}-\operatorname{test}\left(H_{0}: \lambda_{1}=0 \& \lambda_{2}=1\right)
$$

\begin{tabular}{rrrrrrrrrr}
$\lambda_{1}$ & -0.00 & $(0.13)$ & 0.32 & $(0.22)$ & $-0.42^{a}$ & $(0.17)$ & -0.17 & $(0.22)$ & $0.24(0.65)$ \\
$\lambda_{2}$ & $0.80^{a, c}$ & $(0.04)$ & $0.77^{a, c}(0.06)$ & $0.93^{a}$ & $(0.08)$ & $0.69^{a}(0.18)$ & $0.41(0.50)$ \\
& $12.32^{a}$ & & $8.68^{a}$ & & $4.81^{b}$ & & $3.27^{d}$ & & $2.19^{d}$ \\
$R_{\text {adj }}^{2}$ & & 0.873 & & 0.889 & & 0.892 & & 0.781 & -0.120 \\
\hline
\end{tabular}

Notes: Average annual percentage rates. The contributions of the various factors are

the rate of growth of that factor multiplied by the average factor share between $t$ and $t-1$.

$a: \operatorname{sig}$ at $1 \%$

$b: \operatorname{sig}$ at $5 \%$

$c$ : significantly different of unity at $1 \%(F-t e s t)$

$d: F$-test statistic for the period 1991-1999 is 6.77 and significant at $5 \%$

Standard deviation between () 
Topics in Macroeconomics, Vol. 6 [2006], Iss. 2, Art. 2

In form ation forp $=0.5$

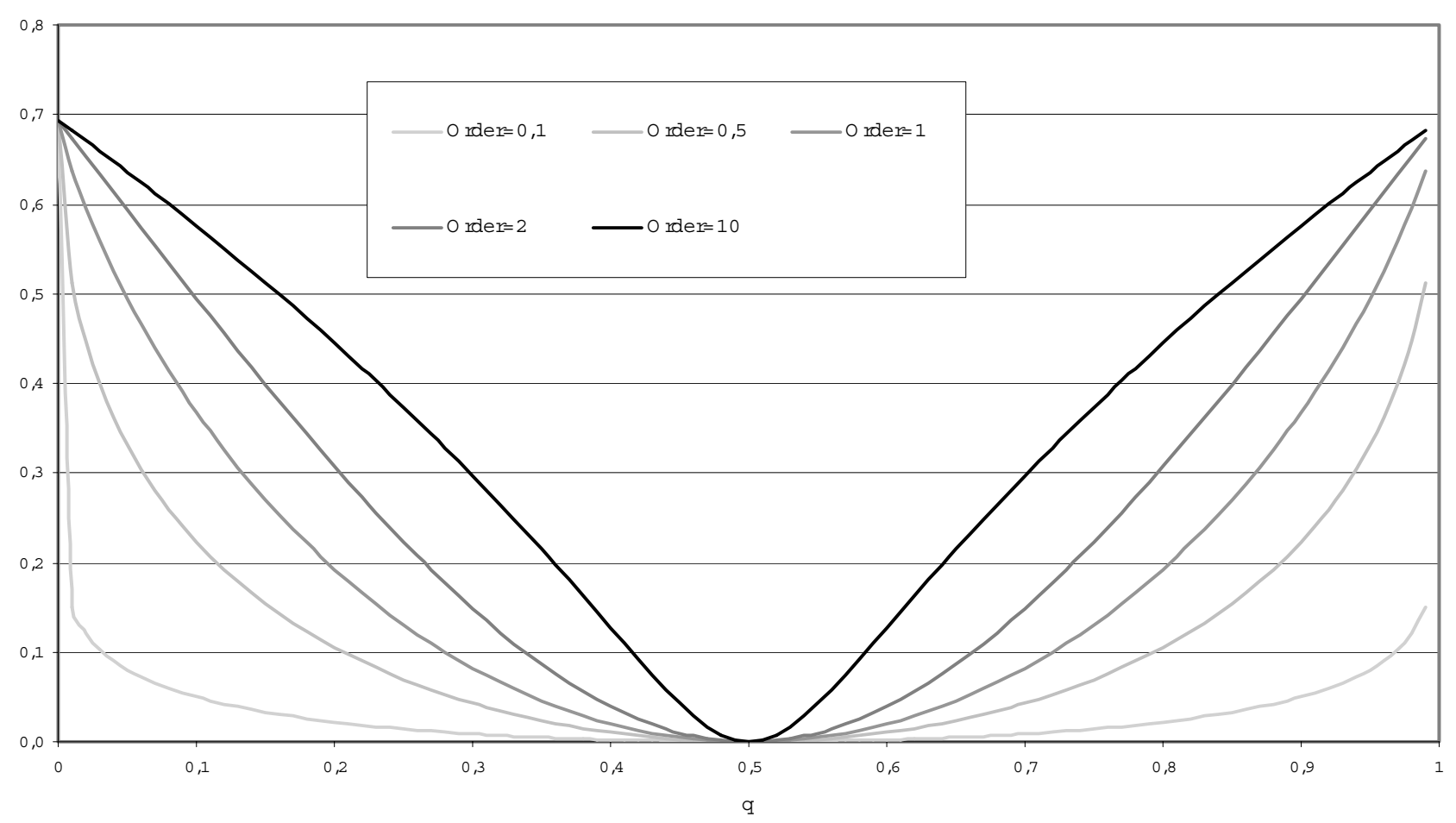

Figure 1: The larger $\alpha$, the faster information increases as the distribution $Q$ diverges from the distribution $P$. 